\title{
INNER-CORE ANISOTROPY AND Rotation
}

\author{
Jeroen Tromp \\ Seismological Laboratory, California Institute of Technology, Pasadena, \\ California 91125; e-mail: jtromp@ gps.caltech.edu
}

\begin{abstract}
Key Words seismology of the core, inner-core boundary, inner-core shear waves, inner-core viscosity, inner-core attenuation
\end{abstract}

- Abstract This paper reviews recent research focused on the Earth's inner core. Large inner-core traveltime anomalies and the anomalous splitting of core-sensitive free oscillations strongly suggest that the inner core is anisotropic. Initial models involved a simple, constant or depth-dependent cylindrical anisotropy at a level less than a few percent. Recent observations suggest that its eastern hemisphere is largely isotropic, whereas its western hemisphere is highly anisotropic, and there are indications that its top $100 \mathrm{~km}$ may be isotropic. The coda of inner-core reflected phases has been used to infer strong heterogeneities with a length scale of just a few kilometers. Thus, a complicated three-dimensional picture of the inner core is beginning to emerge, although it has been suggested that much of this complexity may be the misinterpretation of signals that have their origin in the lowermost mantle. Numerical models of the geodynamo suggest that the inner core may rotate at a slightly different rate than the mantle. Recent seismological estimates based upon traveltime and normal-mode data limit inner-core differential rotation to less than +0.2 degrees per year.

\section{INTRODUCTION}

The existence of the Earth's core was first inferred by Oldham (1906) who noticed that compressional-wave amplitudes decay rapidly beyond epicentral distances of approximately $100^{\circ}$. Such a shadow zone is indicative of a low-velocity region. Gutenberg (1913) estimated the depth of this region to be $2900 \mathrm{~km}$. Figure 1 illustrates the radial compressional $(\mathrm{P})$ velocity profile in the Preliminary Reference Earth Model (PREM) (Dziewonski \& Anderson 1981). Notice that the P velocity drops dramatically from $13.72 \mathrm{~km} / \mathrm{s}$ to $8.06 \mathrm{~km} / \mathrm{s}$ at the core-mantle boundary (CMB). The CMB in PREM is located at a depth of $2891 \mathrm{~km}$, remarkably close to Gutenberg's original estimate. This major discontinuity causes a shadow zone between approximately $100^{\circ}$ and $143^{\circ}$. Beyond $143^{\circ}$ the (outer) core produces two P-wave arrivals: the slower PKP(AB) phase and the faster PKP(BC) phase.

The Earth's inner core was first detected by Lehmann (1936). As shown in Figure 1, the P velocity increases from $10.36 \mathrm{~km} / \mathrm{s}$ to $11.03 \mathrm{~km} / \mathrm{s}$ at the innercore boundary (ICB) with a radius of $1221 \mathrm{~km}$ in PREM. This high-velocity 


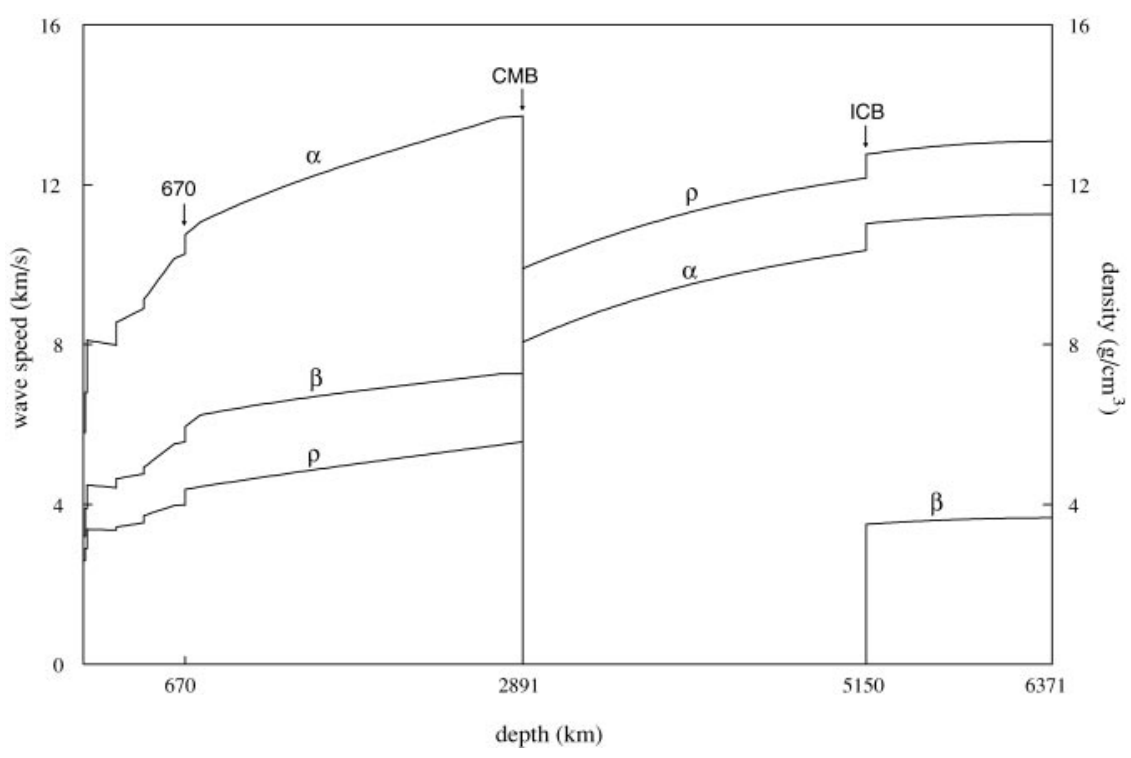

Figure 1 Compressional-wave velocity $\alpha$, shear-wave velocity $\beta$, and density $\rho$ as a function of depth in the isotropic version of the Preliminary Reference Earth Model (PREM) (Dziewonski \& Anderson 1981). The locations of the inner-core boundary (ICB), core-mantle boundary (CMB), and $670 \mathrm{~km}$ discontinuity (670) have been marked. The CMB has the most dramatic contrast in model parameters of all of the Earth's discontinuities, including the free surface.

region introduces a triplication in the $\mathrm{PKP}(\mathrm{BC})$ traveltime curve, thus producing the reflected phase PKP(CB), also known as PKiKP, and the transmitted phase PKP(DF), also referred to as PKIKP. The observation of reflected (PKiKP) arrivals in the core shadow led Lehman (1936) to postulate that there was an inner core with a radius of approximately $1400 \mathrm{~km}$.

The P-velocity drop at the CMB and P-velocity increase at the ICB combine to produce the core traveltime curve shown in Figure 2. The PKP $(\mathrm{AB})$ and $\mathrm{PKP}(\mathrm{BC})$ branches are associated with the outer core, and the PKP(CD) and PKP(DF) branches are associated with the inner core. Figure 3 shows a seismogram for an event in the South Sandwich Islands recorded in College, Alaska, that contains the PKP(DF), PKP(BC), and PKP(AB) phases.

Jeffreys (1926) established that the outer core is fluid based upon an analysis of solid Earth tides and the arrival times of shear (S) waves. Birch (1940) and Bullen (1946) proposed that the jump in P velocity at the ICB is a result of the solidification of an iron-rich alloy, and Birch (1952) predicted the finite shear velocity of the inner core to be $3.4 \mathrm{~km} / \mathrm{s}$. The first observational evidence for a solid inner core came from the Earth's free oscillations, some of whose eigenfrequencies cannot be explained without it (Dziewonski 1971, Dziewonski \& Gilbert 1971). The inner core shear-wave velocity of $3.5 \mathrm{~km} / \mathrm{s}$ preferred by normal modes is very close to 


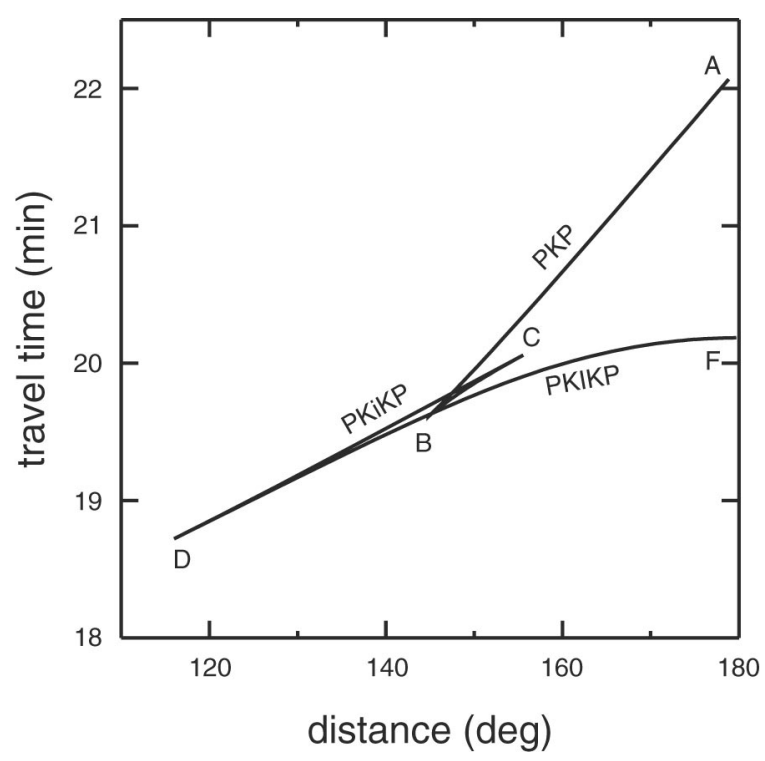

Figure 2 Traveltime curve for compressional waves that travel through the core. The outer core has a much lower compressional-wave velocity than the mantle (see Figure 1). This causes a shadow zone from $100^{\circ}$ to $143^{\circ}$ and gives rise to the $\operatorname{PKP}(\mathrm{AB})$ and $\mathrm{PKP}(\mathrm{BC})$ branches of the traveltime curve beyond $143^{\circ}$. The compressional-wave speed in the inner core is higher than at the bottom of the outer core (see Figure 1). This increase in velocity causes a triplication in the $\mathrm{PKP}(\mathrm{BC})$ traveltime curve leading to the $\mathrm{PKP}(\mathrm{CD})$ and $\mathrm{PKP}(\mathrm{DF})$ branches. The PKP(CD), also called PKiKP, branch corresponds to reflections off the innercore boundary (ICB), and the PKP(DF), or PKIKP, branch corresponds to waves that travel through the inner core. The ray geometry associated with this traveltime curve is shown in Figure 5. PKIKP is observed from approximately $120^{\circ}$ to $180^{\circ}, \mathrm{PKP}(\mathrm{BC})$ from $148^{\circ}$ to $155^{\circ}$, and $\mathrm{PKP}(\mathrm{AB})$ from $150^{\circ}$ to $180^{\circ}$. In principle, the ICB reflected phase PKiKP may be observed from $0^{\circ}$ to $155^{\circ}$. (Courtesy of X Song.)

Birch's (1952) prediction. Figure 1 illustrates the shear velocity profile in PREM. A solid inner core gives rise to body waves that travel through it as shear waves: phases such as PKJKP, SKJKS, or SKJKP (Bullen 1951). Past claims of the detection of such phases (Julian et al 1972) have been controversial (Doornbos 1974).

The Earth's density profile is constrained by spheroidal normal-mode eigenfrequencies and the Earth's mass and principal moment of inertia (Dziewonski \& Anderson 1981); it is illustrated for PREM in Figure 1. Deviations from an adiabatic density profile are characterized by the Bullen (1963) parameter, which is estimated to be $1 \pm 0.05$ for the outer core (Masters 1979). This value is consistent with adiabaticity but does not preclude stably stratified layers at the top and bottom of the outer core. The jump in density at the ICB is estimated to be 0.5-0.6 g/cm³ (Masters \& Shearer 1990, Shearer \& Masters 1990). The Earth's 


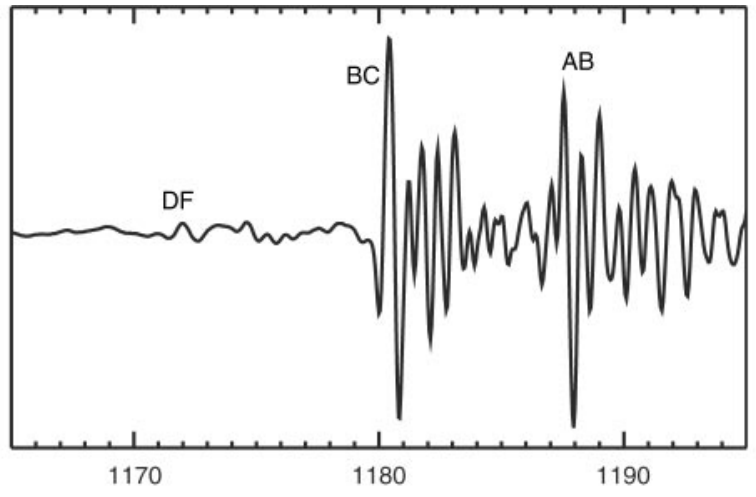

Time (s)

Figure 3 Vertical component seismogram recorded in College, Alaska, after an earthquake in the South Sandwich Islands. The PKP(DF), PKP(BC), and PKP(AB) arrivals have been labeled. See Figure 5 for the PKP ray geometry and Figure 2 for the PKP traveltime curve. Note that the $\operatorname{PKP}(\mathrm{DF})$ is depleted in high frequencies compared to $\mathrm{PKP}(\mathrm{BC})$ and $\mathrm{PKP}(\mathrm{AB})$, indicative of severe attenuation in the inner core. The $\operatorname{PKP}(\mathrm{AB})$ wave has passed through a caustic, i.e. an envelope of rays. As a result of this it is Hilbert transformed, i.e. shifted in phase by $90^{\circ}$, making it an emergent phase that is harder to pick. (Courtesy of X Song.)

Slichter mode, which corresponds to a rigid translation of the inner core relative to the mantle, is uniquely sensitive to the density jump at the ICB, but thus far claims of its detection have remained controversial (e.g. Smylie 1992). Profiles of gravitational acceleration and pressure associated with the PREM density structure are shown in Figure 4. The gravitational acceleration is almost flat throughout the mantle and decreases linearly to zero from the CMB towards the Earth's center. Pressure increases monotonically to a value of $364 \mathrm{GPa}$ at the center.

Only elements with atomic numbers close to iron can be reconciled with the seismic constraints on density (Birch 1964, Allegre et al 1995). This, combined with the cosmic abundances of siderophiles and the existence of the geodynamo, strongly suggests that the core consists of an iron-nickel alloy (Jeanloz 1990, McDonough \& Sun 1995, Stixrude \& Brown 1998). To satisfy seismic constraints on density and bulk modulus requires $10 \%$ of a lighter element in the outer core. Candidates include hydrogen, carbon, nitrogen, oxygen, magnesium, silicon, and sulfur (Birch 1952, Poirier 1994, Allegre et al 1995, Stixrude et al 1997, Merrill et al 1998), but no clear favorite has emerged.

Attenuation within the inner core is particularly difficult to constrain. Most body-wave estimates are based upon the $\mathrm{PKP}(\mathrm{BC}) / \mathrm{PKP}(\mathrm{DF})$ amplitude ratio, which is available over a small epicentral distance range and only samples the top $350 \mathrm{~km}$ of the inner core, with limited radial resolution. A postulated 'mushy zone' of dendrites at the top of the inner core associated with its solidification 

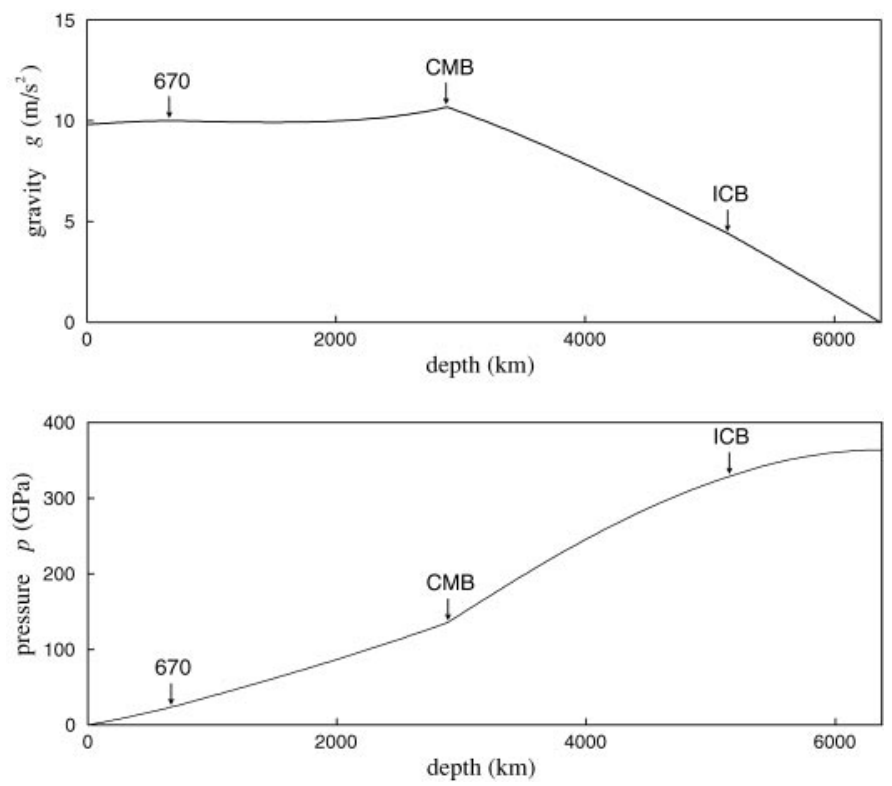

Figure 4 Gravitational acceleration $g$ (top) and hydrostatic pressure $p$ as a function of depth for the radial density distribution in Preliminary Reference Earth Model (PREM) (see Figure 1). Note that gravity is basically flat throughout the mantle and decreases linearly to zero through the core. Pressure increases monotonically from 0 at the Earth's surface to $364 \mathrm{GPa}$ at the Earth's center.

would result in a distinctively low quality factor (Loper \& Roberts 1981, Fearn et al 1981, Loper \& Fearn 1983), but seismological observations of such a zone remain inconclusive. Bhattacharyya et al (1993) and Souriau \& Roudil (1995) find a comparable P-wave quality factor of roughly 360 for the top of the core. This translates into a shear quality factor of 50 , which is distinctly lower than the value of $110 \pm 25$ per cent inferred from normal modes (Widmer et al 1991, Durek \& Ekström 1996). The seismogram in Figure 3 clearly illustrates that the high-frequency content of PKP(DF) is depleted relative to that of $\mathrm{PKP}(\mathrm{BC})$ and $\mathrm{PKP}(\mathrm{AB})$, indicative of severe attenuation within the inner core.

The viscosity of the inner core is another poorly known quantity. Buffett (1997) used geodynamic considerations as well as reported inner-core superrotation (Song \& Richards 1996) and seismic attenuation to limit its viscosity to values less than $10^{17} \mathrm{~Pa}$ s or greater than $10^{20} \mathrm{~Pa}$ s. Mineral physics considerations appear to favor the lower viscosity estimate (Karato 1999), which would imply that the inner core has a viscosity that is at least four orders of magnitude smaller than that of the Earth's mantle.

Despite its small size- $1.5 \%$ of the Earth's mass - the inner core is one of the more intriguing parts of our planet. It appears to be highly anisotropic, and it 
is not unlikely nor unexpected that it rotates at a different rate than the mantle (Gubbins 1981). The remainder of this review focuses on recent research related to the Earth's inner core, in particular its anisotropy and differential rotation. Other recent reviews of inner-core anisotropy and rotation were written by Song (1997) and Creager (2000).

\section{INNER-CORE ANISOTROPY}

Masters \& Gilbert (1981) first observed a spheroidal mode, ${ }_{10} \mathrm{~S}_{2}$, whose splitting cannot be explained in terms of the Earth's rotation, ellipticity, and lateral heterogeneity. There is now a collection of more than 25 so-called anomalously split modes. Poupinet et al (1983) first observed that PKIKP body waves traveling parallel to the Earth's rotation axis arrive faster than waves traveling in the equatorial plane. They explained this observation in terms of a prolate inner core. The concept of inner-core anisotropy was introduced in back-to-back papers by Morelli et al (1986) and Woodhouse et al (1986) as an explanation for both anomalous PKIKP traveltimes and anomalously split modes. Cylindrical anisotropy at the level of a few percent with a fast axis roughly parallel to the Earth's rotation axis and a slow axis in the equatorial plane continues to be the preferred explanation for both sets of observations, although the picture is evolving rapidly. In this section we review recent seismological and mineralogical constraints on inner-core anisotropy and summarize some of the proposed mechanisms.

\subsection{Seismological Constraints}

Seismological constraints on inner-core anisotropy may be subdivided in terms of body-wave and normal-mode observations. Both sets of data play an important role from the start, and in the two sections below we discuss each of them in some depth.

2.1.1 Body Waves Most of what we know about the inner core from a body-wave perspective comes from the analysis of the phase PKP(DF), or PKIKP, although scarce observations of the ICB reflected phase PKP(CD), or PKiKP, put important constraints on the ICB radius and impedance contrast. Figure 5 illustrates the PKP ray geometry in PREM, and the associated traveltime curve is displayed in Figure 2. Inferences about the inner core rely upon direct observations of PKP(DF), which are available in the epicentral distance range of $120^{\circ}-180^{\circ}$, differential traveltime measurements between $\mathrm{PKP}(\mathrm{DF})$ and $\mathrm{PKP}(\mathrm{BC})$, which are available in the distance range of $148^{\circ}-155^{\circ}$, and differential traveltime measurements between PKP(DF) and $\mathrm{PKP}(\mathrm{AB})$, available in the range $150^{\circ}-180^{\circ}$. The advantage of the differential traveltime measurements is that they are less sensitive to heterogeneity near the source and receiver, although the ray paths in the lowermost mantle can be sufficiently different for heterogeneity in this region to have an effect on the differential 


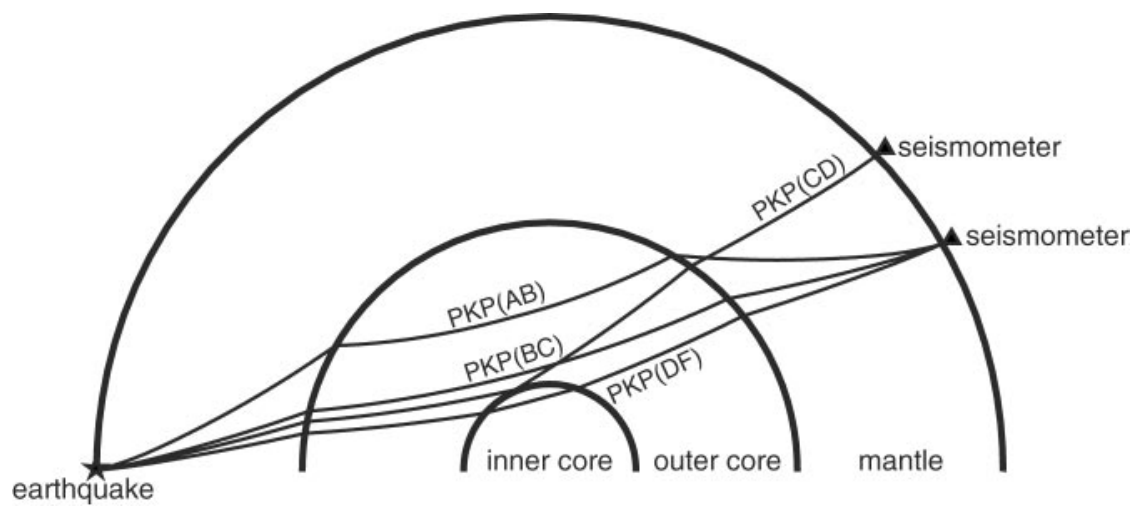

Figure 5 Ray geometry of PKP phases. The associated traveltime curve is shown in Figure 2. Notice that as $\operatorname{PKP}(\mathrm{AB})$ and $\mathrm{PKP}(\mathrm{BC})$ travel through the outer core, $\mathrm{PKP}(\mathrm{CD})$, or PKiKP, is reflected off the inner-core boundary (ICB), and PKP(DF), or PKIKP, travels through the inner core. The compressional-wave velocity in the inner core is rather uniform (see Figure 1), rendering the inner-core leg of the PKIKP ray basically straight. The ray paths of $\operatorname{PKP}(\mathrm{BC})$ and $\mathrm{PKP}(\mathrm{DF})$ are very similar in the mantle, which is why the differential traveltime $\mathrm{PKP}(\mathrm{BC})-\mathrm{PKP}(\mathrm{DF})$ is popular for determining inner-core structure. However, strong lateral gradients in the lowermost mantle may affect this differential traveltime (Bréger et al 1999). The differential traveltime PKP(AB)-PKP(DF) is also used, but notice that the core entry and exit points of $\mathrm{PKP}(\mathrm{AB})$ and $\mathrm{PKP}(\mathrm{DF})$ are well separated, making this differential traveltime sensitive to heterogeneity in the lower mantle (Bréger et al 2000). Near source/receiver contributions are eliminated in the PKP(BC)-PKP(DF) and $\mathrm{PKP}(\mathrm{AB})-\mathrm{PKP}(\mathrm{DF})$ differential traveltime measurements. (Courtesy of $\mathrm{X}$ Song.)

traveltime, in particular for $\operatorname{PKP}(\mathrm{DF})-\mathrm{PKP}(\mathrm{AB})$ (Figure 5). A disadvantage of the $\mathrm{PKP}(\mathrm{DF})-\mathrm{PKP}(\mathrm{BC})$ differential traveltime measurements is that they sample only the top $350 \mathrm{~km}$ of the inner core, but a big advantage is their quality. Absolute PKP traveltimes are routinely picked and provided by the International Seismological Centre (ISC). Although the quality of the ISC observations is not as good as that of the hand-picked differential traveltime measurements, the large quantity of observations - hundreds of thousands - and the better three-dimensional coverage compensate for this. From $130^{\circ}$ to $145^{\circ}$ PKIKP is frequently contaminated because of small-scale scattering in the lower mantle (Haddon \& Cleary 1974).

Renewed interest in the inner core was sparked by Creager (1992), who found large PKP(DF)-PKP(BC) differential traveltime anomalies for paths from the South Sandwich Islands to Alaska. Creager's observations were confirmed by Song \& Helmberger (1993), McSweeney et al (1997) and Vinnik et al (1994). Reanalysis of the ISC PKIKP data by Su \& Dziewonski (1995) also confirmed large traveltime anomalies, and Shearer (1994) concluded that studies by Shearer et al (1988) and Shearer \& Toy (1991) underestimated the required level of inner-core anisotropy. 
Initial body-wave models of inner-core anisotropy were fairly simple: the anisotropy was either uniform throughout the inner core or had a simple depth dependence, and the required level of anisotropy was less than a few percent. Several groups reported a tilt of the symmetry axis of the anisotropy relative to the Earth's rotation axis (Shearer \& Toy 1991, Creager 1992, Su \& Dziewonski 1995). Since then the models have become more and more elaborate. Song \& Helmberger $(1995,1998)$ proposed that the top $100 \mathrm{~km}$ of the inner core are isotropic, something that would be difficult to reconcile with normal-mode observations (Durek \& Romanowicz 1999). Perhaps the most surprising recent observation is that there appears to be a distinct difference between, roughly, the eastern and western hemispheres of the inner core. Both Tanaka \& Hamaguchi (1997) and Creager (1999) report that waves traveling almost parallel to the Earth's rotation axis arrive about $4 \mathrm{~s}$ faster in the western hemisphere, but that similar paths in the eastern hemisphere show only a $1 \mathrm{~s}$ anomaly. These observations suggest a strong degree one pattern in anisotropy, with a highly anisotropic western hemisphere and a weakly anisotropic eastern hemisphere. These inferences are based upon differential traveltime anomalies that mainly constrain the top $400 \mathrm{~km}$ of the inner core.

Creager (1997) documents rapid variations in the strength of anisotropy for paths from the South Sandwich Islands to Alaska, and Song (2000) reports similar variations in heterogeneity. A new approach to the subject was introduced by Vidale \& Earle (2000) who used the coda of short period ICB reflections, i.e. PKiKP phases, to investigate small-scale inner-core heterogeneity. To explain the observed PKiKP coda, Vidale \& Earle (2000) estimate that they need innercore heterogeneity at the level of a few percent with length scales of about $2 \mathrm{~km}$, which would make the inner core one of the more heterogeneous parts of the Earth.

In two important recent papers, Bréger et al $(1999,2000)$ argue that much of the scatter in $\mathrm{PKP}(\mathrm{BC})-\mathrm{PKP}(\mathrm{DF})$ and $\mathrm{PKP}(\mathrm{AB})-\mathrm{PKP}(\mathrm{DF})$ differential traveltime anomalies can be explained in terms of strong heterogeneity in the lowermost mantle. As shown in Figure 5, the core entry points for $\mathrm{PKP}(\mathrm{DF})$ and $\mathrm{PKP}(\mathrm{AB})$ are separated by several thousand kilometers. The lowermost mantle exhibits strong lateral variations on this scale and thus can seriously influence the $\operatorname{PKP}(A B)-$ PKP(DF) differential traveltimes. The core entry points for PKP(DF) and PKP(BC) are separated by only a few hundred kilometers. Therefore, an explanation of PKP(BC)-PKP(DF) traveltime anomalies in terms of lowermost mantle heterogeneity requires very strong lateral gradients. Nevertheless, the tradeoff between lower mantle heterogeneity and inner-core structure must be taken very seriously.

2.1.2 Normal Modes The normal modes of a spherically symmetric Earth model, i.e. a model that is a function of radius only, e.g. PREM, may be subdivided in terms of spheroidal and toroidal modes. At shorter period, spheroidal modes correspond to compressional waves and vertically polarized shear waves, socalled P-SV motion, whereas toroidal modes correspond to horizontally polarized 
shear waves, so-called SH motion. In the context of surface waves, spheroidal modes correspond to Rayleigh waves whereas toroidal modes correspond to Love waves. Spheroidal modes are labeled ${ }_{n} \mathrm{~S}_{l}$ and toroidal modes ${ }_{n} \mathrm{~T}_{l}$, where integers $n=0,1,2, \ldots$ denote the overtone number and integers $l=0,1,2, \ldots$ denote the angular degree. The modes or multiplets ${ }_{n} \mathrm{~S}_{l}$ and ${ }_{n} \mathrm{~T}_{l}$ consist of $2 l+1$ singlets. In a spherically symmetric Earth model, each singlet within a given multiplet has exactly the same frequency of oscillation $_{n} \omega_{l}$. The Earth's rotation, ellipticity, and lateral heterogeneity causes the singlets to split, such that each singlet acquires its own distinct frequency of oscillation (Dahlen \& Tromp 1998). Normal-mode seismologists observe the splitting of the Earth's free oscillations and try to explain it in terms of large-scale variations in structure.

Every normal mode 'sees' the structure of the Earth differently. Some modes are predominantly sensitive to the shear-velocity structure of the mantle, while other modes see a combination of shear and compressional velocities. There are observable modes that see all the way into the inner core, whereas others are confined to the crust. How a given normal mode samples the structure of the Earth is determined by kernels that describe a mode's sensitivity to compressional velocity, shear velocity, and density as a function of depth. In Figure 6 the kernels of the mantle-sensitive spheroidal mode ${ }_{1} \mathrm{~S}_{4}$ and the core-sensitive spheroidal mode ${ }_{6} \mathrm{~S}_{3}$ are displayed.

A convenient way to visualize normal-mode splitting is provided by the splitting function, which was first introduced by Giardini et al (1987). Basically, at a given location on the surface, a mode's splitting function represents a local radial average of the Earth's three-dimensional structure. By plotting the value of the splitting function everywhere on the surface we can visualize how a certain mode averages the Earth's three-dimensional variations in velocity and density structure. Figure 7 (top) shows the observed splitting function for spheroidal mode ${ }_{1} \mathrm{~S}_{4}$, as well as a predicted splitting function based upon shear-velocity model SKS12WM13 (Dziewonski et al 1997). Clearly there is excellent agreement between the observed and predicted splitting function for this mantle-sensitive mode. Figure 7 (bottom) illustrates that this is not the case for the core-sensitive mode ${ }_{6} \mathrm{~S}_{3}$ : a large, mainly zonal, degree two signal is missing. This unexpectedly large signal is referred to as anomalous splitting (Ritzwoller et al 1986, 1988; Li et al 1991; Widmer et al 1992; He \& Tromp 1996; Resovsky \& Ritzwoller 1998; Durek \& Romanowicz 1999).

Although inner-core anisotropy has been generally accepted as an explanation for the anomalous PKIKP traveltimes, it was initially not embraced as the cause of anomalous normal-mode splitting. The simple transversely isotropic model proposed by Woodhouse et al (1986) was updated by a more general and elaborate model ( $\mathrm{Li}$ et al 1991). Widmer et al (1992) more than doubled the number of observed anomalously split modes, and when the anisotropic inner-core model of Li et al (1991) failed to explain the anomalous splitting of the new observations, Widmer et al (1992) rejected inner-core anisotropy as the cause of the splitting. Because some of the anomalously split modes have less than $3 \%$ of their energy 


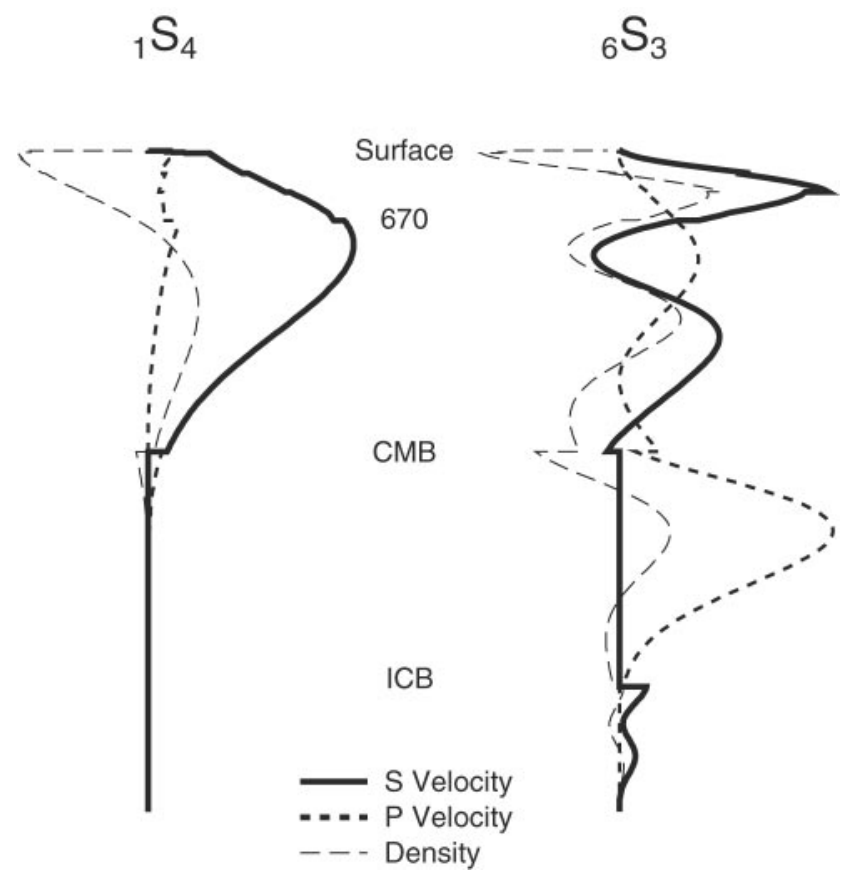

Figure 6 Sensitivity kernels (degree zero) of mantle-sensitive mode ${ }_{1} \mathrm{~S}_{4}$ (left) and innercore-sensitive mode ${ }_{6} \mathrm{~S}_{3}$ (right). The solid line represents sensitivity to shear velocity perturbations as a function of depth, the short-dashed line sensitivity to compressional velocity, and the long-dashed line sensitivity to density. The locations of the $670 \mathrm{~km}$ discontinuity, the core-mantle boundary (CMB), and the inner-core boundary (ICB) have been indicated. Mode ${ }_{1} \mathrm{~S}_{4}$ is not sensitive to structure in the inner core, whereas the anomalously split mode ${ }_{6} \mathrm{~S}_{3}$ 'sees' the inner core.

in the inner core, Widmer et al (1992) speculated that the outer core might be the origin of the splitting. It is difficult to justify lateral variations in density larger than one part in $10^{5}$ in the fluid outer core (Stevenson 1987, J Bloxham and BA Buffett, personal communication). This probably means that the outer core does not support significant variations in bulk modulus either, making it highly unlikely that the outer core is the cause of the anomalous splitting. Zonal degree two topography on the CMB is restricted to less than a few hundred meters based upon verylong baseline interferometry (Gwinn et al 1986), and reasonable topography on the ICB cannot explain the observed anomalous splitting either. Tanimoto (1989) showed that the Earth's magnetic field cannot be responsible for the splitting, and Gilbert (1994) showed that flow in the outer core is not responsible either.

Tromp (1993, 1994, 1995) demonstrated that a simple transversely anisotropic inner-core model explained the anomalous splitting of modes, the anomalous PKP(DF)-PKP(BC) differential traveltimes of Creager (1992), and the absolute PKP(DF) traveltimes of Su \& Dziewonski (1995) reasonably well. Since then, 


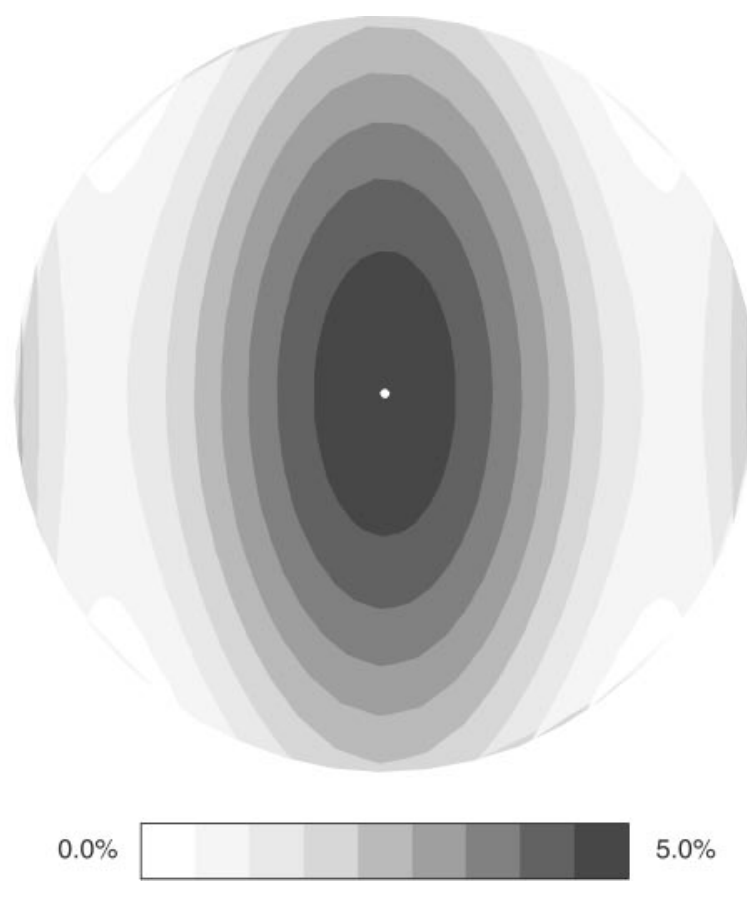

Figure 8 Cross section through the axisymmetric anisotropic inner-core model of Durek \& Romanowicz (1999). The contour levels show the compressional-velocity perturbations relative to Preliminary Reference Earth Model (PREM) for waves traveling parallel to the rotation axis. Note that this inner-core model is highly anisotropic near its center. The pattern of velocity perturbations is reminiscent of degree one solid-state thermal convection, which is one of the proposed mechanisms for the anisotropy (Jeanloz \& Wenk 1988, Wenk et al 1988). (Courtesy of J Durek.)

Romanowicz et al (1996) and Durek \& Romanowicz (1999) have revisited the more general axisymmetric model parameterization of Li et al (1991). Romanowicz and colleagues argue that, in particular, the zonal degree four normal-mode splitting parameters are a better fit with a model such as that shown in Figure 8. Recently, Romanowicz \& Bréger (2000) have argued that the anomalous splitting may be explained in terms of heterogeneity in the outer core, a suggestion originally advocated by Widmer et al (1992). The problem with this solution is that, as mentioned earlier, there are very strong arguments against outer-core heterogeneity at a level greater than roughly one part in $10^{5}$.

\subsection{Mineralogical Constraints}

The seismological constraints on the structure of the inner core have important implications for its composition, growth, and internal dynamics. As mentioned in the introduction, the core consists mainly of iron with roughly $10 \%$ of an 
unidentified lighter element (Birch 1952, Poirier 1994, Allegre et al 1995, Stixrude et al 1997, Merrill et al 1998). The seismic properties of the inner core are therefore tightly determined by the phase diagram of iron.

Experimentally, only diamond-anvil and shock wave experiments can reach inner-core pressures and temperatures (e.g. Shen \& Heinz 1998, Stixrude \& Brown 1998). First principles density functional theory (Stixrude et al 1994, $1998 \mathrm{a}, \mathrm{b})$ has been used extensively to theoretically determine the properties of iron. Three phases of iron under core conditions have thus far been determined (Stixrude \& Brown 1998): body-centered cubic (bcc), face-centered cubic (fcc), and hexagonal-close packed (hcp) iron. The hcp or $\epsilon$ phase of iron appears to be the preferred phase of iron in the core (Brown \& McQueen 1986, Stixrude \& Cohen 1995b). Theoretical calculations by Stixrude \& Cohen (1995a) suggest that the bcc phase is unstable under inner-core conditions, and Stixrude \& Cohen (1995b) argue that hcp iron best explains the seismic observations. The latter study implies a highly organized anisotropic fabric, which includes the possibility that the inner core is a giant single crystal. In contrast, recent experiments by Mao et al (1998) indicate a higher level of anisotropy requiring substantially less alignment.

\subsection{Mechanisms}

Solid-state convection, the Earth's magnetic field, solidification texturing, and anisotropic growth have all been proposed as possible mechanisms responsible for the observed inner-core anisotropy. In the following sections we briefly review all of these mechanisms. Thus far, there is no clear favorite.

2.3.1 Inner-Core Convection The first mechanism proposed as an explanation for the nearly cylindrical anisotropy involves thermal convection of the inner core (Jeanloz \& Wenk 1988, Wenk et al 1988). This mechanism requires a dominant degree one mode of solid-state convection driven by radioactive heat sources. Normal-mode studies by Romanowicz et al (1996) and Durek \& Romanowicz (1999) suggest that cylindrical models of anisotropy, in which the fast axis is not perfectly aligned with the rotation axis, explain the mode data slightly better. An example of such a cylindrical model is shown in Figure 8. The question is whether the inner core convects at all (Weber \& Machetel 1992), and, if it does, or did at some point in its past, whether the dominant mode of convection would be degree one. Furthermore, the amount of heat production required for solid state convection and the high thermal conductivity of iron make inner-core convection unlikely (Yukutake 1998).

2.3.2 Magnetic Field Karato (1993) proposed that iron crystals have an anisotropic magnetic susceptibility that causes them to be aligned by the Earth's magnetic field as they precipitate on the ICB. Alternatively, Karato (1999) proposed 
that flow induced by Maxwell stresses caused by the Earth's magnetic field near the ICB produces an axisymmetric, seismically anisotropic fabric. In both cases the main concern is whether or not the magnetic field is sufficiently strong for the alignment process to work.

2.3.3 Solidification Texturing Bergman (1997) proposed that inner-core anisotropy may be a result of solidification texturing, which is caused by dendritic growth of iron crystals. The proposed dendrites grow along an axis that is aligned with the direction of dominant heat flow. Bergman (1997) envisions predominant inner-core cooling in a direction perpendicular to the rotation axis, resulting in similarly oriented dendrites. The dendritic fabric that is the result of this process is responsible for the observed anisotropy and is also in agreement with a suggested depth dependence of the strength of the anisotropy. The model predicts a strong anisotropy in seismic attenuation that has thus far only been hinted at (Souriau \& Romanowicz 1996).

\subsection{Anisotropic Growth}

Yoshida et al (1996) proposed that the Earth's inner core grows faster in its equatorial regions than in its polar regions because heat transport is less effective near the poles. They envision that viscous flow from the equator to the poles to maintain hydrostatic equilibrium induces stresses that are sufficiently large to cause axial crystal alignment. Yoshida et al (1996) obtain reasonable agreement with the observed orientation and level of anisotropy based upon Kamb's (1959) model for stress-induced preferred orientation and the elastic parameters for hcp iron determined by Stixrude \& Cohen (1995a). The issue here is the viscosity of the inner core: If it is as small as proposed by Buffett (1997), the flow induced stresses may not be large enough to align the crystals on a reasonable time scale (Karato 1999).

\section{INNER-CORE DIFFERENTIAL ROTATION}

Numerical models of the geodynamo predict that the inner core can rotate at a slightly different rate than the mantle (Glatzmaier \& Roberts 1995, 1996; Kuang $\&$ Bloxham 1997). The predicted differential rotation, on the order of degrees per year, was sufficiently large to motivate Song \& Richards (1996) to search for it by using the suggested tilt of the symmetry axis of the anisotropy (Su \& Dziewonski $1995)$ as a marker. If the inner core exhibits a differential rotation relative to the mantle, PKIKP waves traveling from the same source to the same receiver sample different portions of the inner core over time. If the properties of the inner core vary spatially (or temporally!), the PKIKP traveltime anomalies vary with time. Figure 9 illustrates seismograms recorded at College, Alaska, for earthquakes in the 


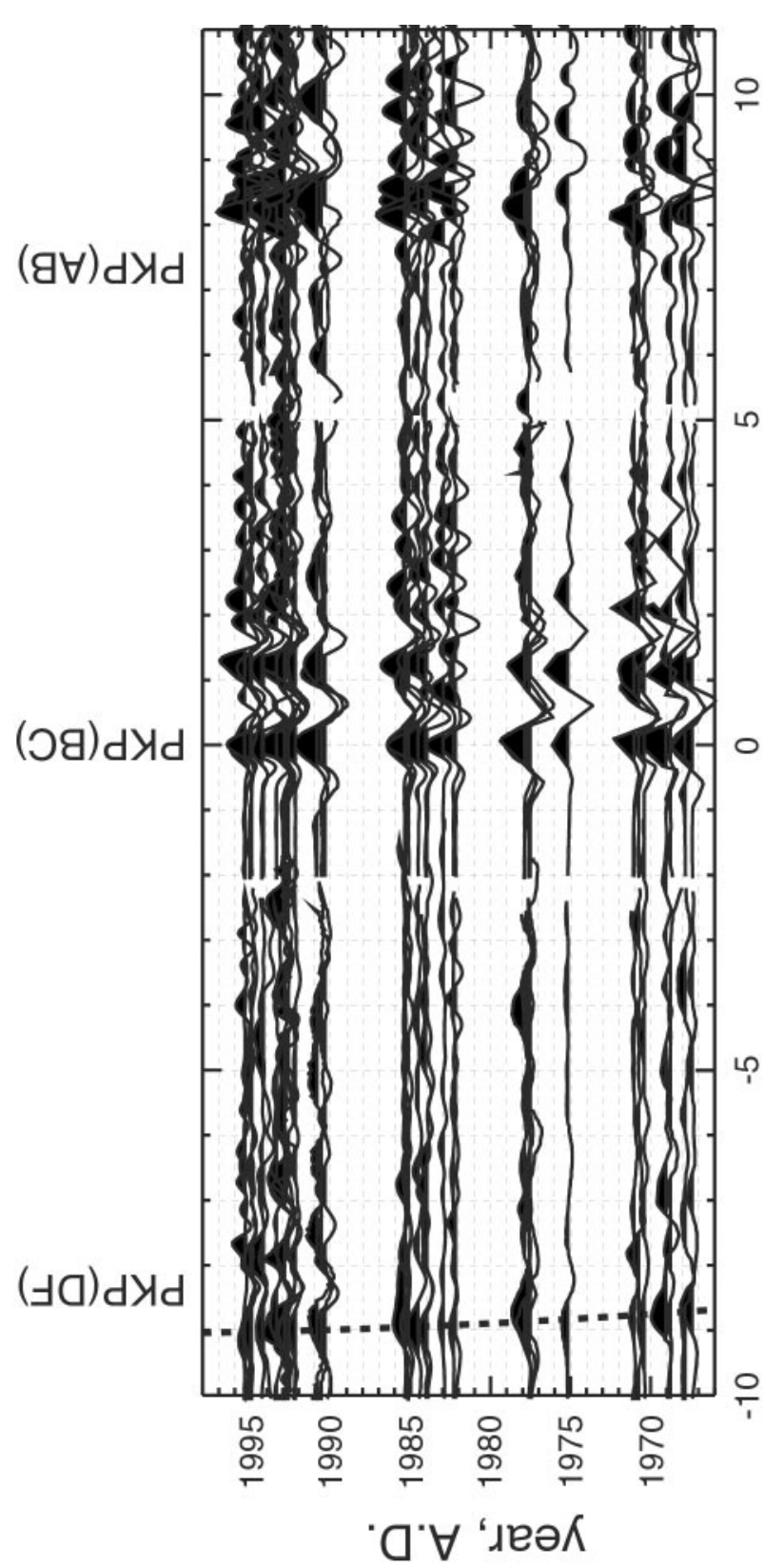

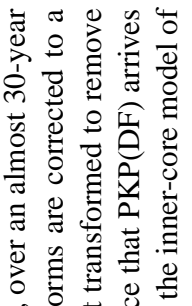

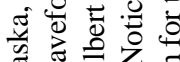

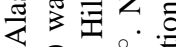

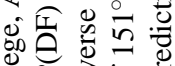

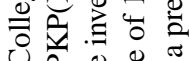

O

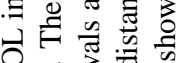

U。

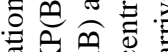

( ) $\frac{\pi}{2} \leq$

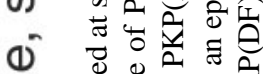

死

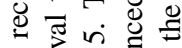

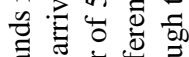

类

ธี

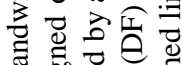

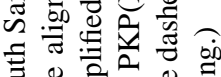

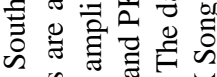

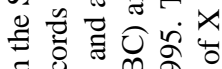

$\Xi$ Ð

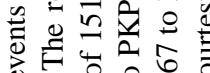

टज

பn்

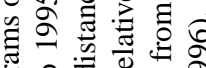

응

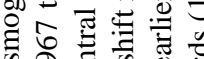

可 的造

क ह 늉 $\frac{0}{0}$.

a 웡

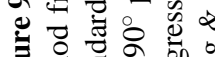

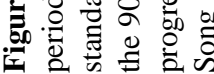


South Sandwich Islands, an epicentral distance of about $151^{\circ}$, over a period of 28 years. The records are aligned on the arrival time of $\mathrm{PKP}(\mathrm{BC})$ and clearly show the PKP(DF) phase arriving earlier in more recent years. From this observation Song \& Richards (1996) inferred an eastward inner-core rotation at a rate of 1.1 degrees per year. Su et al (1996), using ISC reported PKIKP traveltime anomalies, also inferred a super-rotation of the inner core but at a three times higher rate. A subsequent reanalysis of their data and method lead Dziewonski \& Su (1998) to conclude that the differential rotation rate is indistinguishable from zero. The original papers by Song \& Richards (1996) and Su et al (1996) created much interest in the subject of inner-core rotation. In the three sections below we review recent body-wave, normal-mode, and geodynamic constraints on differential rotation of the inner core.

\subsection{Body-Wave Constraints}

The original paper by Song \& Richards (1996) relied upon a tilt in the symmetry axis of the anisotropy relative to the Earth's spin axis for a marker. Souriau et al (1997) argued that this tilt cannot be reliably determined because it may be biased by paths from the South Sandwich Islands to Alaska. Su et al's (1996) differential rotation rate estimate relied upon temporal variations in the three-dimensional pattern of inner-core anisotropy over a period of 30 years. Creager (1997) used 30 years of PKP(DF)-PKP(BC) differential traveltimes recorded in College, Alaska, and earthquakes in the South Atlantic to limit the differential rotation rate of the inner core to less than $0.2-0.3$ degrees per year; his estimate is based upon a lateral anisotropy gradient rather than a tilted symmetry axis. Under the assumptions of Song \& Richards (1996), the perceived rotation rate trades off with the level of anisotropy and the orientation of the symmetry axis, whereas Creager's (1997) rotation rate trades off with the size of the anisotropy gradient. Souriau et al (1997) observe a correlation between the PKP(BC)-PKP(DF) differential traveltimes and the event magnitude distribution, again putting an explanation in terms of differential rotation into question. Subsequent studies by Souriau (1998a) and Souriau \& Poupinet (2000) limit the differential rotation rate to less than 1 degree per year, and a study by Poupinet et al (2000) based upon teleseismic doublets, a pair of earthquakes occurring nearly at the same location and exhibiting similar waveforms, limits it to less than 0.2 degrees per year.

Perhaps the most serious concern about the inference of differential rotation is its trade-off with event mislocation. Over the years the network used to locate earthquakes has evolved considerably, and furthermore, earthquakes in the Southern Hemisphere are notoriously difficult to locate (Souriau 1998b). Nevertheless, Song \& Li (2000) and Song (2000) report rates of 0.3-1.1 degrees per year and rely upon inhomogeneities in anisotropy for a marker. Vidale et al (2000) take the analysis of PKiKP coda (Vidale \& Earle 2000) further by using it to constrain inner-core differential rotation. They use Russian and French nuclear tests and 
seismic arrays in Norway and the United States to determine shifts in the PKiKP coda over time, which they interpret in terms of an inner-core differential rotation rate of 0.2 degrees per year.

\subsection{Normal-Mode Constraints}

The splitting functions of core-sensitive modes can be corrected for the effects of structure in the mantle. Figure 7 illustrates that the predicted splitting functions for mantle-sensitive modes are in remarkably good agreement, suggesting that this correction should be adequate. The remaining signal is presumably caused by structure in the core, and as the outer core is expected to be laterally homogeneous, this puts the origin of the signal in the inner core. By investigating mantle-corrected splitting functions of core-sensitive modes over a time span of a few decades, one can look for temporal variations in the splitting functions consistent with a uniform differential rotation. Sharrock \& Woodhouse (1998) first looked for a slow longitudinal shift in the splitting functions of several core-sensitive modes, but they failed to detect a consistent differential rotation, partly because of the limited number of suitable seismograms 20 years ago. Recently, Laske \& Masters (1999) used 20 years of free-oscillation data to rule out a differential rotation rate of 1 degree per year but report that their data are "marginally consistent" with a rate of 0.2-0.3 degrees per year (see Figure 10). Their preferred rotation rate, however, is zero, suggesting that the inner core is gravitationally locked to the mantle (Buffett 1996a,b). The advantage of the mode studies over the traveltime studies is that the former do not rely upon the determination of small-scale heterogeneities in the inner core because they are insensitive to these.

\subsection{Geodynamic Constraints}

Lateral heterogeneities in the Earth's mantle produce aspherical gravity anomalies. The ICB can be deformed by as much as $100 \mathrm{~m}$ by these anomalies, and this provides a mechanism for gravitationally locking the inner core to the mantle, much like the Moon is gravitationally locked to the Earth. The electromagnetic torques exerted on the inner core by the geodynamo are estimated to be too weak to break this lock, putting differential inner-core rotation into question (Buffett 1996a,b, 1997). However, Buffett (1997) also showed that if the viscosity of the inner core is less than $3 \times 10^{16} \mathrm{~Pa} \mathrm{~s}$, which is rather low, the inner core can flow to accommodate the differential rotation induced by the geodynamo while maintaining the ICB topography induced by the gravity anomalies. Aurnou et al (1996) explain the proposed super-rotation in terms of the structure of convection and the associated geodynamo action in the outer core. Buffett \& Creager (1999) show that length-of-day variations can only be reconciled with inner-core superrotation if the associated torque on the mantle is matched by an electromagnetic torque that is caused by westward flow at the top of the core. 


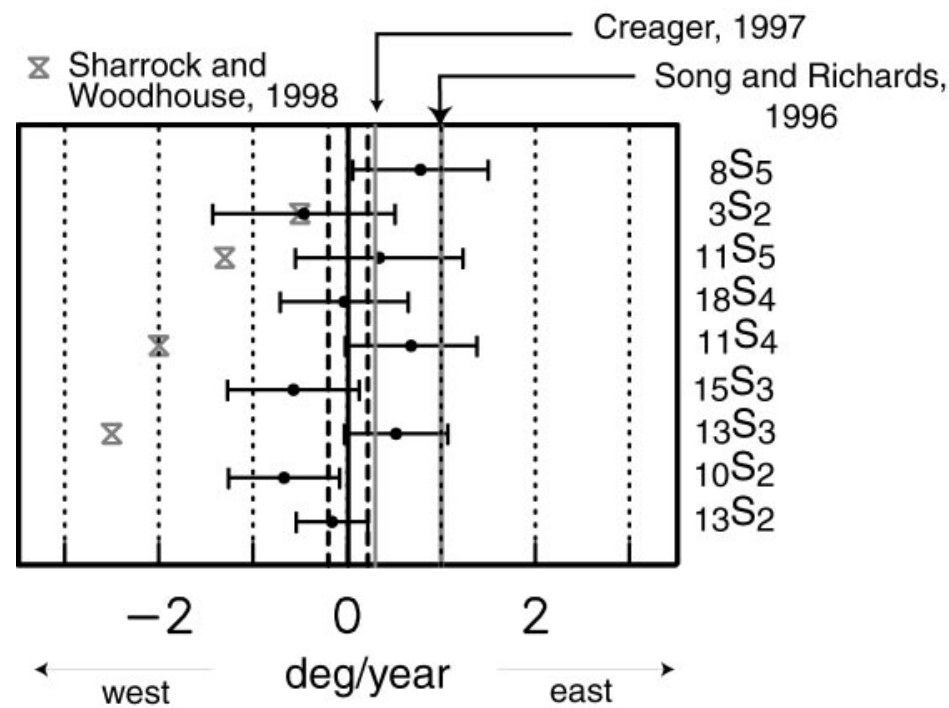

Figure 10 Inner-core rotation rates inferred from temporal longitudinal variations in the splitting functions of nine core-sensitive modes listed in the column on the right. Laske \& Masters (1999) used 20 years of digital data to infer a mean rotation rate of $0.01 \pm 0.21$ degrees per year, suggesting that the inner core is gravitationally locked to the mantle (Buffett 1996a,b). Results from a normal-mode study by Sharrock \& Woodhouse (1998) and traveltime studies by Song \& Richards (1996) and Creager (1997) are shown for comparison. (Courtesy of G Laske.)

\section{INNER-CORE SHEAR WAVES}

The solidity of the Earth's inner core was established in the early seventies based upon normal-mode evidence (Dziewonski 1971, Dziewonski \& Gilbert 1971). Such a solid inner core supports a variety of body waves that travel though it as a shear wave and that, in theory, should be detectable at the Earth's surface (Bullen 1951). Early claims of the detection of such phases, in particular PKJKP, have remained controversial (e.g. Julian et al 1972, Doornbos 1974).

Two recent papers have readdressed this issue. Okal \& Cansi (1998) report the detection of PKJKP based upon an analysis of seismograms produced by the June 17, 1996, deep Flores Sea event recorded in France. Their estimated inner-core shear-wave velocity of $3.65 \mathrm{~km} / \mathrm{s}$ is in good agreement with normal-mode constraints. Deuss et al (2000) analyzed data from the same event at 47 stations around the globe based upon a nonlinear phase-weighted stacking technique (Schimmel \& Paulssen 1997) in the frequency range $0.01-0.1 \mathrm{~Hz}$. The stacks show energy at the expected arrival times and slownesses of PKJKP and SKJKP + pPKJKP. By comparing their observed stacks to synthetic stacks for PREM with and without a solid inner core, Deuss et al unambiguously identify arrivals related to the solid 
inner core. They demonstrate that the PKJKP detection reported by Okal \& Cansi (1998) may be a misidentification and that data from the great June 9, 1994, Bolivia earthquake do not show unambiguous inner-core shear phases. Deuss et al (2000) emphasize that inner-core shear phases can only be observed at longer periods because strong attenuation at shorter periods wipes out the signal (Doornbos 1974). Their preferred inner-core shear-wave velocity of $3.6 \mathrm{~km} / \mathrm{s}$ is in excellent agreement with that in PREM (see Figure 1).

\section{DISCUSSION}

A large number of recent papers have argued for strong variations in inner-core anisotropy. Besides a distinct difference in the level of anisotropy in the inner core's eastern and western hemispheres, sharp local gradients, and the presence of strong scatterers have been inferred, and it has been suggested that the inner core's top $100 \mathrm{~km}$ are isotropic.

Personally, I find it difficult to imagine how the inner core could be very heterogeneous. It has been slowly crystallizing in a homogeneous outer core over billions of years. I would expect the result of this slow crystallization process to be a very homogeneous, smooth inner core with hardly any lateral variations whatsoever. Gravitationally induced inner-core deformations are expected to be relatively small, and the associated lateral variations should also be minimal (Buffett 1996a,b). However, it is likely that systematic, slow growth has led to a high degree of texturing and that this frozen fabric is responsible for the inferred anisotropy (Bergman 1997). My personal preference would be to keep inner-core models as simple as possible and to try and explain observed complications in inner-core traveltime anomalies in terms of a mantle origin (Bréger et al 1999, 2000). Geodynamicists strongly believe that outer core variations in density and bulk modulus are well below the limits of seismic detectability; therefore one should try to avoid putting heterogeneity in the outer core as well (Stevenson 1987).

Inferences based upon body waves and free oscillations limit inner-core differential rotation to less than about +0.2 degrees per year. The main difference between the two approaches is that body waves rely upon strong small-scale heterogeneity in the inner core as a marker, whereas normal mode inferences are based upon slow longitudinal changes in very long-wavelength structure. The chief concern about the traveltime estimates of differential rotation is that perceived temporal variations in PKIKP arrival times could be the result of systematic earthquake mislocations. The main issues regarding the normal-mode rotation estimates are the accuracy of the required correction for mantle heterogeneity and the quality of the splitting functions, especially for the earlier years.

It would seem that Deuss et al (2000) have finally detected inner-core shear waves. Their body-wave observations confirm mode inferences in the early seventies (Dziewonski 1971, Dziewonski \& Gilbert 1971) that the inner core is solid. Perhaps the next decade will reveal inner-core shear-wave anisotropy! 


\section{ACKNOWLEDGMENTS}

I thank Joe Durek, Miaki Ishii, Gabi Laske, and Xiaodong Song for providing some of the figures for this paper.

\section{Visit the Annual Reviews home page at www.AnnualReviews.org}

\section{LITERATURE CITED}

Allegre CJ, Poirier JP, Humler E, Hofmann AW. 1995. The chemical composition of the Earth. Earth Planet. Sci. Lett. 134:515-26

Aurnou JM, Brito D, Olson PL. 1996. Mechanics of inner core super-rotation. Geophys. Res. Lett. 23:3401-4

Bergman MI. 1997. Measurements of elastic anisotropy due to solidification texturing and the implications for the Earth's inner core. Nature 389:60-63

Bhattacharyya J, Shearer P, Masters G. 1993. Inner core attenuation from short-period PKP(BC) versus PKP(DF) waveforms. Geophys. J. Int. 114:1-11

Birch F. 1940. The aplha-gamma transformation of iron at high pressures, and the problem of the Earth's magnetism. Amer. J. Sci. 238:192-211

Birch F. 1952. Elasticity and constitution of the Earth's interior. J. Geophys. Res. 57:22786

Birch F. 1964. Density and composition of the mantle and core. J. Geophys. Res. 69:437788

Bréger L, Romanowicz B, Tkalčić H. 1999. PKP(BC-DF) travel time residuals and short scale heterogeneity in the deep earth. Geophys. Res. Lett. 26:3169-72

Bréger L, Tkalčić H, Romanowicz B. 2000. The effect of D" on PKP(AB-DF) travel time residuals and possible implications for inner core structure. Earth Planet. Sci. Lett. 175:133-43

Brown JM, McQueen RG. 1986. Phase transitions, Grüneisen parameter, and elasticity for shocked iron between $77 \mathrm{GPa}$ and $400 \mathrm{GPa}$. J. Geophys. Res. 91:7485-94

Buffett BA. 1996a. A mechanism for decade fluctuations in the length of day. Geophys. Res. Lett. 23:3803-6

Buffett BA. 1996b. Gravitational oscillation in the length of day. Geophys. Res. Lett. 23:2279-82

Buffett BA. 1997. Geodynamic estimates of the viscosity of the Earth's inner core. Nature 388:571-73

Buffett BA, Creager KC. 1999. A comparison between geodetic and seismic estimates of inner core rotation. Geophys. Res. Lett. 26:1509-12

Bullen KE. 1946. A hypothesis on compressibility at compressionals of the order a million atmospheres. Nature 157:405

Bullen KE. 1951. Theoretical amplitudes of the seismic phase PKJKP. Mon. Not. R. Astron. Soc. Geophys. Suppl. 6:163-167

Bullen KE. 1963. An Introduction to the Theory of Seismology. Cambridge: Cambridge Univ. Press, $381 \mathrm{pp}$.

Creager KC. 1992. Anisotropy of the inner core from differential travel times of the phases PKP and PKIKP. Nature 356:309-14

Creager KC. 1997. Inner core rotation rate from small-scale heterogeneity and time-varying travel times. Science 278:1284-88

Creager KC. 1999. Large-scale variations in inner core anisotropy. J. Geophys. Res. 102: 23127-39

Creager KC. 2000. Inner core anisotropy and rotation. In Seismic Tomography and Mineral Physics. Washington, DC: Am. Geophys. Union. In press

Dahlen FA, Tromp J. 1998. Theoretical Global Seismology. Princeton: Princeton Univ. Press. 1025 pp.

Deuss A, Woodhouse JH, Paulssen H, Trampert 
J. 2000. The observation of inner core shear waves. Geophys. J. Int. 142:67-73

Doornbos DJ. 1974. The anelasticity of the inner core. Geophys. J. R. Astron. Soc. 38:397415

Durek JJ, Ekström G. 1996. A radial model of anelasticity consistent with long-period surface wave attenuation. Bull. Seismol. Soc. Am. 86:144-58

Durek JJ, Romanowicz B. 1999. Inner core anisotropy inferred by direct inversion of normal mode spectra. Geophys. J. Int. 139:599622

Dziewonski AM. 1971. Overtones of free oscillations and the structure of the Earth's interior. Science 172:1336-38

Dziewonski AM, Anderson DL. 1981. Preliminary reference Earth model. Phys. Earth Planet. Inter. 25:297-356

Dziewonski AM, Gilbert F. 1971. Solidity of the inner core of the Earth inferred from normal mode observations. Nature 234:46566

Dziewonski AM, Liu X-F, Su W-J. 1997. Lateral heterogeneity in the lowermost mantle. In Earth's Deep Interior, ed. DJ Crossley, 11-50. Newark, NJ: Gordon \& Breach

Dziewonski AM, Su W-J. 1998. A local anomoly in the inner core. EOS 79:S218 (Abstr.)

Fearn DR, Loper DE, Roberts PH. 1981. Structure of the Earth's inner core. Nature 292:232-33

Giardini D, Li X-D, Woodhouse JH. 1987. Three-dimensional structure of the Earth from splitting in free oscillation spectra. $\mathrm{Na}$ ture 325:405-11

Gilbert F. 1994. Splitting of the free-oscillation multiplets by steady flow. Geophys. J. Int. 116:227-29

Glatzmaier GA, Roberts PH. 1995. A threedimensional convective dynamo solution with rotating and finitely conducting inner core and mantle. Phys. Earth Planet. Inter. 91:63-75

Glatzmaier GA, Roberts PH. 1996. Rotation and magnetism of Earth's inner core. Science 274:1887-91
Gubbins D. 1981. Rotation of the inner core. $J$. Geophys. Res. 86:11695-99

Gutenberg B. 1913. Über die Konstitution des Erdinnern, erschlossen aus Erdbebenbeobachtungen. Z. Geophys. 14:1217-18

Gwinn CR, Herring TA, Shapiro II. 1986. Geodesy by radio interferometry: studies of the forced nutations of the Earth 2. Interpretation. J. Geophys. Res. 91:4755-65

Haddon RAW, Cleary JR. 1974. Evidence for scattering of seismic PKP waves near the mantle-core boundary. Phys. Earth Planet. Inter. 8:211-34

He X, Tromp J. 1996. Normal-mode constraints on the structure of the Earth. J. Geophys. Res. 101:20053-82

Jeanloz R. 1990. The nature of the Earth's core. Annu. Rev. Earth Planet. Sci. 18:357-86

Jeanloz R, Wenk H-R. 1988. Convection and anisotropy of the inner core. Geophys. Res. Lett. 15:72-75

Jeffreys H. 1926. The rigidity of the Earth's central core. Mon. Not. R. Astron. Soc. Geophys. Suppl. 1:371-83

Julian BR, Davies D, Sheppard RM. 1972. PKJKP. Nature 235:317-18

Kamb WB. 1959. Theory of preferred crystal orientation developed by crystallization under stress. J. Geol. 67:153-170

Karato S. 1993. Inner core anisotropy due to magnetic field-induced preferred orientation of iron. Science 262:1708-11

Karato S. 1999. Seismic anisotropy of Earth's inner core caused by Maxwell stress-induced flow. Nature 402:871-73

Kuang W, Bloxham J. 1997. An Earth-like numerical dynamo model. Nature 389:371-74

Laske G, Masters G. 1999. Rotation of the inner core from a new analysis of free oscillations. Nature 402:66-69

Lehmann I. 1936. P'. Bur. Cent. Seismol. Int. A 14:3-31

Li X-D, Giardini D, Woodhouse JH. 1991. Large-scale three-dimensional even-degree structure of the Earth from splitting of long-period normal modes. J. Geophys. Res. 96:551-77 
Loper DE, Fearn DR. 1983. A seismic model of a partially molten inner core. J. Geophys. Res. 88:1235-42

Loper DE, Roberts PH. 1981. A study of conditions at the inner core boundary of the Earth. Phys. Earth Planet. Inter. 24:302-7

Mao H-K, Shu J, Shen G, Hemley RJ, Li B, Singh AK. 1998. Elasticity and rheology of iron above $220 \mathrm{GPa}$ and the nature of Earth's inner core. Nature 396:741-43

Masters G. 1979. Observational constraints on the chemical and thermal structure of the Earth's interior. Geophys. J. R. Astron. Soc. 57:507-34

Masters G, Gilbert F. 1981. Structure of the inner core inferred from observations of its spheroidal shear modes. Geophys. Res. Lett. 8:569-71

Masters G, Shearer PM. 1990. Summary of seismological constraints on the structure of the Earth's core. J. Geophys. Res. 95:21691-95

McDonough WF, Sun S-S. 1995. The composition of the Earth. Chem. Geol. 120:22353

McSweeney TJ, Creager KC, Merrill RT. 1997. Depth extend of inner-core seismic anisotropy and implications for geomagnetism. Phys. Earth Planet. Inter. 101:13156

Merrill RT, McElhinny MW, McFadden PL. 1998. The Magnetic Field of the Earth: Paleomagnetism, the Core and the Deep Mantle. San Diego: Academic. 531 pp.

Morelli A, Dziewonski AM, Woodhouse JH. 1986. Anisotropy of the inner core inferred from PKIKP travel times. Geophys. Res. Lett. 13:1545-48

Okal EA, Cansi Y. 1998. Detection of PKJKP at intermediate periods by progressive multichannel correlation. Earth Planet. Sci. Lett. 164:23-30

Oldham RD. 1906. Constitution of the interior of the Earth as revealed by earthquakes. $Q$. J. Geol. Soc. 62:456-75

Poirier J-P. 1994. Light elements in the Earth's outer core: a critical review. Phys. Earth Planet. Inter. 85:319-37
Poupinet GR, Pillet R, Souriau A. 1983. Possible heterogeneity of the Earth's core deduced from PKIKP travel times. Nature 305: 204-6

Poupinet G, Souriau A, Coutant O. 2000. The existence of an inner core super-rotation questioned by teleseismic doublets. Phys. Earth Planet. Inter. 108:77-88

Resovsky JS, Ritzwoller MH. 1998. New and refined constraints on three-dimensional Earth structure from normal modes below 3 mHz. J. Geophys. Res. 103:783-810

Ritzwoller M, Masters G, Gilbert F. 1986. Observations of anomalous splitting and their interpretation in terms of aspherical structure. J. Geophys. Res. 91:10203-28

Ritzwoller M, Masters G, Gilbert F. 1988. Constraining aspherical structure with lowdegree interaction coefficients: application to uncoupled multiplets. J. Geophys. Res. 93: 6369-96

Romanowicz B, Bréger L. 2000. Anomalous splitting of free oscillations: a re-evaluation of possible interpretations. J. Geophys. Res. 105:21,559-78

Romanowicz B, Li X-D, Durek JJ. 1996. Anisotropy in the inner core; could it be due to low-order convection? Science 274:96366

Schimmel M, Paulssen H. 1997. Noise reduction and the detection of weak, coherent signals through phase-weighted stacks. Geophys. J. Int. 130:497-505

Sharrock DS, Woodhouse JH. 1998. Investigation of time dependent inner core structure by the analysis of free oscillation spectra. Earth Planet. Space 50:1013-18

Shearer PM. 1994. Constraints on inner core anisotropy from ISC PKP(DF) data. J. Geophys. Res. 99:19647-59

Shearer PM, Masters G. 1990. The density and shear velocity contrast at the inner core boundary. Geophys. J. Int. 102:491-98

Shearer PM, Toy KM, Orcutt JA. 1988. Axisymmetric earth models and inner core anisotropy. Nature 333:228-32

Shearer PM, Toy KM. 1991. PKP(BC) versus 
PKP(DF) differential travel times and aspherical structure in the Earth's inner core. J. Geophys. Res. 96:2233-47

Shen G, Heinz DL. 1998. High-pressure melting of deep mantle and core materials. In Ultrahigh-Pressure Mineralogy: Physics and Chemistry of the Earth's Deep Interior, ed. RJ Hemley, 37:369-96. Washington, DC: Mineral. Soc. Am.

Smylie DE. 1992. The inner core translational triplet and the density near the Earth's center. Science 255:1678-82

Song X. 1997. Anisotropy of the Earth's inner core. Rev. Geophys. 35:297-313

Song X. 2000. Joint inversion for inner core rotation, inner core anisotropy, and mantle heterogeneity. J. Geophys. Res. 105:7931-43

Song X, Helmberger DV. 1993. Anisotropy of the Earth's inner core. Geophys. Res. Lett. 20:2591-94

Song X, Helmberger DV. 1995. Depth dependence of anisotropy of Earth's inner core. J. Geophys. Res. 100:9805-16

Song X, Helmberger DV. 1998. Seismic evidence for an inner core transition zone. Science 282:924-27

Song X, Li A. 2000. Support for differential inner core superrotation from earthquakes in Alaska recorded at South Pole station. J. Geophys. Res. 105:623-30

Song X, Richards PG. 1996. Seismological evidence for differential rotation of the Earth's inner core. Nature 382:221-24

Souriau A. 1998a. Earth's inner core: Is the rotation real? Science 281:55-56

Souriau A. 1998b. New seismological constraints on differential rotation of the inner core from Novaya Zemblya events recorded at DRV, Antarctica. Geophys. J. Int. 134:F1F5

Souriau A, Poupinet G. 2000. Inner core rotation: a test at the worldwide scale. Phys. Earth Planet. Inter. 118:13-27

Souriau A, Romanowicz B. 1996. Anisotropy in inner core attenuation: a new type of data to constrain the nature of the solid core. Geophys. Res. Lett. 23:1-4
Souriau A, Roudil P. 1995. Attenuation in the uppermost inner core from broad-band GEOSCOPE PKP data. Geophys. J. Int. 123:57287

Souriau A, Roudil P, Moynot B. 1997. Inner core differential rotation: facts and artefacts. Geophys. Res. Lett. 24:2103-6

Stevenson DJ. 1987. Limits on lateral density and velocity variations in the Earth's outer core. Geophys. J. R. Astron. Soc. 88:311-19 Stixrude L, Brown JM. 1998. The Earth's core. In Ultrahigh-Pressure Mineralogy: Physics and Chemistry of the Earth's Deep Interior, ed. RJ Hemley, 37:261-82. Washington, DC: Mineral. Soc. Am.

Stixrude L, Cohen RE. 1995a. Constraints on the crystalline structure of the inner core: mechanical instability of BCC iron at high pressure. Geophys. Res. Lett. 22:125-28

Stixrude L, Cohen RE. 1995b. High-pressure elasticity of iron and anisotropy of Earth's inner core. Science 267:1972-75

Stixrude L, Cohen RE, Singh DJ. 1994. Iron at high pressure: linearized augmented plane wave computations in the generalized gradient approximation. Phys. Rev. B 50:644245

Stixrude L, Cohen RE, Hemley RJ. 1998a. Theory of minerals at high pressure. In Ultrahigh-Pressure Mineralogy: Physics and Chemistry of the Earth's Deep Interior, ed. RJ Hemley, 37:261-82. Washington, DC: Mineral. Soc. Am.

Stixrude L, Wasserman E, Cohen RE. 1997. Composition and temperature of Earth's inner core. J. Geophys. Res. 102:24729-39

Stixrude L, Wasserman E, Cohen RE. 1998b. First-principles investigations of solid iron at high pressure and implications for the Earth's inner core. In Properties of Earth and Planetary Materials at High Pressure and Temperature, ed. MH Manghnani, T Yagi, pp. 15971. Washington, DC: Am. Geophys. Union

$\mathrm{Su}$ WJ, Dziewonski AM. 1995. Inner core anisotropy in three dimensions. J. Geophys. Res. 100:9831-52

Su WJ, Dziewonski AM, Jeanloz R. 1996. 
Planet within a plane: rotation of the inner core. Science/ 274:1883-87

Tanaka S, Hamaguchi H. 1997. Degree one heterogeneity and hemispherical variations of anisotropy in the inner core form $\operatorname{PKP}(\mathrm{BC})$ PKP(DF) times. J. Geophys. Res. 102:292538

Tanimoto T. 1989. Splitting of normal modes and travel time anomalies due to the magnetic field of the Earth. J. Geophys. Res. 94:303036

Tromp J. 1993. Support for anisotropy of the Earth's inner core. Nature 366:678-81

Tromp J. 1994. Normal mode splitting due to inner core anisotropy. Geophys. J. Int. 121:963-68

Tromp J. 1995. Normal mode splitting observations from the great 1994 Bolivia and Kuril Island earthquakes: constraints on the structure of the mantle and core. GSA Today 5:137

Vidale JE, Dodge DA, Earle PS. 2000. Slow differential of the Earth's inner core indicated by temporal changes in scattering. Nature 405:445-48

Vidale JE, Earle PS. 2000. Fine-scale heterogeneity in the Earth's inner core. Nature 404:273-75

Vinnik L, Romanowicz B, Bréger L. 1994.
Anisotropy in the center of the inner core. Geophys. Res. Lett. 21:1671-74

Weber P, Machetel P. 1992. Convection within the inner core and thermal implications. Geophys. Res. Lett. 19:2107-10

Wenk H-R, Takeshita T, Jeanloz R. 1988. Development of texture and elastic anisotropy during deformation of hep metals. Geophys. Res. Lett. 15:76-79

Widmer R, Masters G, Gilbert F. 1991. Spherically symmetric attenuation within the Earth from normal mode data. Geophys. J. Int. 104:541-53

Widmer R, Masters G, Gilbert F. 1992. Observably split multiplets-data analysis and interpretation in terms of large-scale aspherical structure. Geophys. J. Int. 111:559-76

Woodhouse JH, Giardini D, Li X-D. 1986. Evidence for inner core anisotropy from splitting in free oscillation data. Geophys. Res. Lett. 13:1549-52

Yoshida SI, Sumita I, Kumazawa M. 1996. Growth model of the inner core coupled with the outer core dynamics and the resulting elastic anisotropy. J. Geophys. Res. 101:28085-103

Yukutake T. 1998. Implausibility of thermal convection in the Earth's solid inner core. Phys. Earth Planet. Inter. 108:1-13 


\section{Observed}

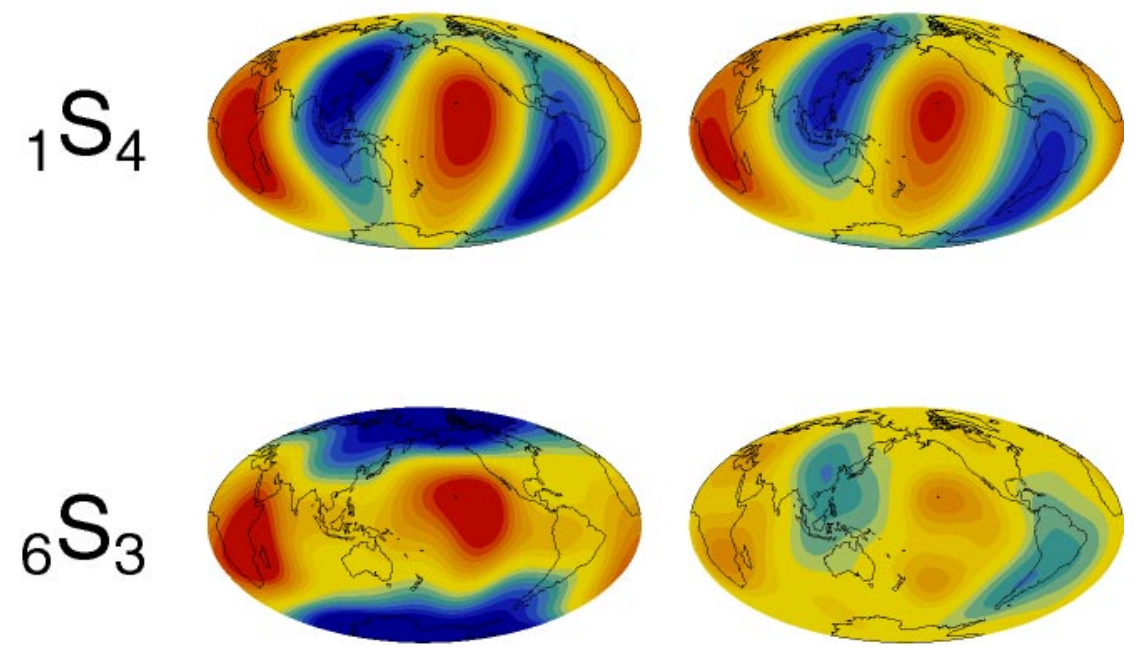

Predicted

Figure 7 Observed (left column) and predicted (right column) splitting functions for mantle-sensitive normal mode ${ }_{1} \mathrm{~S}_{4}$ (top row) and inner-core-sensitive mode ${ }_{6} \mathrm{~S}_{3}$ (bottom row). The predicted splitting function is based upon shear-velocity model SKS12WM13 (Dziewonski et al 1997). The splitting function of the mantle-mode ${ }_{1} \mathrm{~S}_{4}$ is well predicted by SKS12WM13, but the splitting of the core-sensitive mode ${ }_{6} \mathrm{~S}_{3}$ is not: A large, zonal degree two pattern is missing. Such zonal splitting functions are characteristic of all anomalousy split modes. The splitting function represents a local radial average of the Earth's structure. This average value is obtained by filtering the Earth's three-dimensional heterogeneity through kernels such as those shown in Figure 6. Because each mode has a unique set of sensitivity kernels, then each mode also has its own unique splitting function that reflects the way in which it 'sees' the Earth. Splitting functions may be determined directly from free oscillation spectra. 


\section{CONTENTS}

BREAKTHROUGHS IN OUR KNOWLEDGE AND

UNDERSTANDING OF THE EARTH AND PLANETS, G Schubert

HUMAN IMPACTS ON ATMOSPHERIC CHEMISTY, PJ Crutzen, $J$

Lelieveld

INNER-CORE ANISOTROPY AND ROTATION, Jeroen Tromp

PARTIAL MELTING EXPERIMENTS ON PERIDOTITE AND ORIGIN OF MID-OCEAN RIDGE BASALT, Ikuo Kushiro

TECTONIC EVOLUTION OF THE JAPANESE ISLAND ARC SYSTEM, Asahiko Taira

THE ROLE OF PLANTS IN CONTROLLING RATES AND

PRODUCTS OF WEATHERING: Importance of Biological Pumping, $Y$ Lucas

RUSTY RELICS OF EARTH HISTORY: Iron(III) Oxides, Isotopes, and Surficial Environments, Crayton Yapp

USING SPRINGS TO STUDY GROUNDWATER FLOW AND

ACTIVE GEOLOGIC PROCESSES, Michael Manga

GROUND PENETRATING RADAR FOR ENVIRONMENTAL

APPLICATIONS, Rosemary Knight

229

DATING MODERN DELTAS: Progress, Problems, and Prognostics,

Jean-Daniel Stanley

RHEOLOGICAL PROPERTIES OF WATER ICE--APPLICATIONS TO

SATELLITES OF THE OUTER PLANETS, WB Durham, LA Stern

THE LATE ORDOVICIAN MASS EXTINCTION, Peter M Sheehan

HYDROGEN IN THE DEEP EARTH, Quentin Williams, Russell J.

Hemley

PHYSICS OF PARTIALLY SATURATED POROUS MEDIA: Residual Saturation and Seismic-Wave Propagation, Xun Li, Lirong Zhong, Laura J Pyrak-Nolte

RESPONSE OF LATE CARBONIFEROUS AND EARLY PERMIAN PLANT COMMUNITIES TO CLIMATE CHANGE, William A

DiMichele, Hermann W Pfefferkorn, Robert A Gastaldo

GIANT DIKE SWARMS: Earth, Venus, and Mars, RE Ernst, EB

Grosfils, D Mège

489

THE CARBON BUDGET IN SOILS, Ronald Amundson

CONTINUOUS FREE OSCILLATIONS: Atmosphere-Solid Earth 